\title{
Inaugural editorial
}

\author{
G. Alexander Patterson, MD, ${ }^{a}$ Spencer McGrath, MA, ${ }^{\text {b,c }}$ Lindsay Dankmyer, BA, ${ }^{\text {b,c }}$ Tammy Brodie, MA, ${ }^{\text {b,c }}$ \\ and Amy Swartz, BFA ${ }^{\text {b,d,e }}$
}

It is my privilege to serve as Editor-in-Chief of the Journal of Thoracic and Cardiovascular Surgery (JTCVS) and the associated journals of the American Association for Thoracic Surgery (AATS). It is humbling indeed to succeed Dr Richard Weisel and the other legendary surgeons who have served as Editor-in-Chief. I have known Richard for more than 40 years and have long admired his commitment to academic excellence. Among many other awards, he is the 2010 recipient of the AATS Scientific Achievement Award. Dr Weisel has transformed the JTCVS, recruited a new editorial team, reconfigured the editorial board leadership, and expanded the global reach of the JTCVS - all while maintaining very high standards of scholarly publishing.

This editorial team is committed to maintaining these high standards. Our goal is to continue to provide the highest-quality, state-of-the-art cardiothoracic surgery content for the JTCVS readership while also ensuring authors have a satisfying publication experience when submitting their work. We will commit to diversity and inclusion among the editorial board leadership. We plan to give voice and recognition to the editorial board. Readership and author surveys will inform future directions for JTCVS.

Under Dr Weisel's leadership, the open access journals JTVCS Open and JTCVS Techniques were launched and have been very successful to date. We anticipate rapid growth for both open access publications. In 2021, Operative Techniques in Thoracic and Cardiovascular Surgery began increasing the amount of peer-reviewed technique articles per publication, which has allowed us to highlight a wider variety of important techniques. Seminars in Thoracic and Cardiovascular Surgery has similarly increased publication output, and we will discuss new publication opportunities for Seminars in addition to the facilitated manuscript transfers from JTCVS. In addition, the

\footnotetext{
From the ${ }^{\mathrm{a}}$ Washington University School of Medicine, St Louis, Mo; ${ }^{\mathrm{b}}$ American Association for Thoracic Surgery Journals; ${ }^{\mathrm{c}}$ Journal of Thoracic and Cardiovascular Surgery; ${ }^{\mathrm{d}}$ Seminars in Thoracic and Cardiovascular Surgery; and ${ }^{\mathrm{e}}$ Operative Techniques in Thoracic and Cardiovascular Surgery.

Disclosures: The authors reported no conflicts of interest.

The Journal policy requires editors and reviewers to disclose conflicts of interest and to decline handling or reviewing manuscripts for which they may have a conflict of interest. The editors and reviewers of this article have no conflicts of interest.

Received for publication Oct 29, 2021; revisions received Oct 29, 2021; accepted for publication Oct 29, 2021; available ahead of print Nov 9, 2021.

Address for reprints: G. Alexander Patterson, MD, Barnes-Jewish Hospital, One Barnes-Jewish Hospital Plaza, 1 Barnes Hospital Plaza Queeny Tower 3108, 660 South Euclid Campus Box 8234, St Louis, MO 63110 (E-mail: pattersona@ wustl.edu).

J Thorac Cardiovasc Surg 2022;163:1

$0022-5223 / \$ 36.00$

Copyright (c) 2021 by The American Association for Thoracic Surgery

https://doi.org/10.1016/j.jtcvs.2021.10.055
}

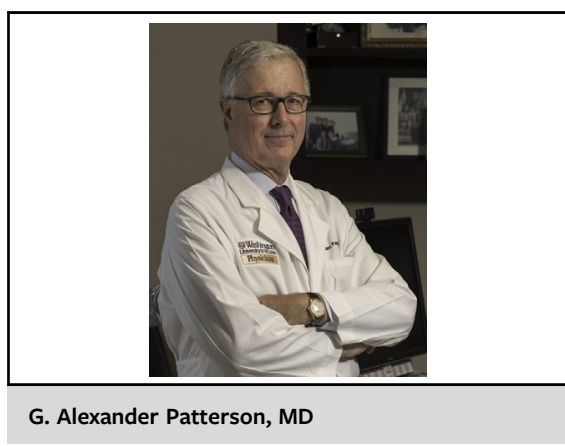

\begin{abstract}
CENTRAL MESSAGE
Our goal at the AATS Journals is to enhance the author experience, bolster diversity and inclusion, and continue to provide the highest-quality, state-of-the-art cardiothoracic surgery content.
\end{abstract}

2021 issue of Pediatric Annual featured a collection of 12 excellent articles stemming from the 2020 AATS Annual Meeting that all congenital heart surgeons should read.

Successful initiatives such as the AATS Journal Alerts have helped to develop the digital communication of articles from AATS Journals. All members and interested readers can sign up on the AATS website to receive bimonthly email alerts about featured papers in each specialty. Most recently, more than 5000 articles from the 6 AATS journals are searchable directly from the AATS website at aats.org/journalsearch. We will focus on the continued development of the digital presence of the AATS journals, especially where there are opportunities for deeper integration with AATS online platforms. The more integrated the AATS journals are with the AATS digital universe, the better equipped we will be to navigate future transformations in scholarly and online publishing.

Other initiatives are being planned and will be evident in forthcoming JTCVS issues over the next few months. Such efforts will be made with constant consideration of the preeminent position of the JTCVS in global cardiothoracic surgery and the core values of the AATS: vision, leadership, scholarship. 